\title{
The Brazilian Digital Television System Access Device Architecture
}

\author{
Eduardo Rodrigues de Carvalho, Gil Garcia de Barros, Laisa Caroline de Paula Costa, Regis Rossi \\ Alves Faria, Rogério Pernas Nunes, Roseli de Deus Lopes \& Marcelo Knörich Zuffo
}

\author{
Laboratório de Sistemas Integráveis \\ Departamento de Engenharia de Sistemas Eletrônicos \\ Escola Politécnica da USP \\ Av. Prof. Luciano Gualberto Trav. 3 n. 158 \\ 05508-900 SP São Paulo Brazil \\ \{eduardo, gil, laisa, regis, nunes, roseli, mkzuffo\}@1si.usp.br
}

\begin{abstract}
In early 2003, the Brazilian government accelerated the decision process on analog to digital transition of terrestrial TV broadcast infrastructure, naming this initiative The Brazilian Digital Television System (SBTVD). This paper describes the access device architecture we have proposed for the SBTVD, as well as related issues. We focused on several requirements among which: flexibility to support the social economical diversity enabling market implementations that can vary on cost, complexity and applications; digital inclusion targeting a minimal cost architecture providing a simple access device to information and services by convergent broadcast and point-to-point telecommunication means; and scalability targets incorporating state-of-the-art technology, considering emerging services and the current legacy analog TV infrastructure available in Brazil. We cover the following specific topics: an architecture overview considering scalability, interoperability and regional and international requirements, operating system and middleware interfaces, audio and video coding formats and associate standards, technical and economical analysis, usability and user interface consistency. Finally two prototypes for the outlined access device architecture are reported.
\end{abstract}

Keywords: interactive Digital TV (iDTV), The Brazilian Digital Television System (SBTVD), Access Device Architecture, digital broadcasting, digital television (DTV), high definition TV (HDTV), Digital Television Services, audio and video coding.

\section{Introduction}

This paper presents the access device architecture we have proposed for the Brazilian Digital Television System (SBTVD). Considering the digital enhancement of audio and video services as well as emerging interactive services, we designated the Digital Television (DTV) receiver as the interactive Digital TV (iDTV) access device. The access device, which also has several denominations in literature, such as set-top-box, TV receiver, home-hub and DTV home server, among others [2], is a critical part of analog-to- digital TV transition in developing countries since it needs to have a minimal cost, shall incorporate digital inclusion features, and requires scalability, both temporal scalability and functional scalability, to incorporate all current and future functions and associated standards adopted.

Over the past two decades there were intense research, development and standardization activities worldwide related to the analog-to-digital transition of the terrestrial broadcast TV infrastructure [1]. These efforts resulted on established standards [9] such as the 
Advanced Television Systems Committee (ATSC) proposed by the United States of America, the Digital Video Broadcasting (DVB) proposed by the European Union and the Integrated Services Digital Broadcasting (ISDB) ([5], [6], [10]) proposed by Japan.

Section 2 introduces the scope of the activities developed during the period between 2003 and 2005 that resulted in the current technologies and standards adopted in Brazil DTV. This section presents briefly the requirements of the proposed architecture. Section 3 outlines the architecture overview describing its layers, the block diagram and associated standards. Section 4 describes the operating system functionalities that interface the physical layer to software layers such as the middleware, resident applications and future software infrastructure. Section 5 presents the audio and video coding formats and associated standards; a particular attention is given to this section considering that these blocks are dominant in terms of access device final cost. Also, the decisions in this block affect the whole transmission environment. Section 6 describes usability and user interface (UI) issues related to the access device, and particular focus is given to consistency. Section 7 describes the technical and economical analysis of the proposed architecture, the analysis methodology considers the SBTVD requirements described in section 2. Section 8 presents experimental evaluations based on some access devices implemented.

\section{THE BRAZILIAN DIGITAL TELEVISION SYSTEM}

Since 1992 the scientific and technical community in broadcasting worldwide has been debating the terrestrial TV analog-to-digital transition. Between 1997 and 2000 Brazilian researchers compared modulation technologies of the DVB, ATSC and ISDB in the São Paulo city. In November 26th 2003 the 4901 Presidential Act [11] was published launching the SBTVD with the following governmental requirements:

- Wide access to all social classes;

- Interoperability;

- Mobility and portability;

- Robustness considering local geographical environment;

- Usability;

- Digital Inclusion.

In $29^{\text {th }}$ July 2006 the decision about core SBTVD technologies was made and published in the 5820 Presidential Act [12]. The ISDB-T modulation was chosen as the reference transmission platform for the SBTVD system [12]. The main criteria adopted to select this modulation platform were robustness and flexibility [3]. The ISDB-T modulation scheme also called BST COFDM (Band Segmented Transmission Coded OFDM) was developed to broadcast digital terrestrial TV with the use of flexible modulation [3]. The $6 \mathrm{MHz}$ channel band is divided into 13 segments of $429 \mathrm{KHz}$ widths each. In those 13 segments, it is possible to transmit simultaneous programs with different robustness and modulation techniques [4]. A requirement from Brazilian broadcaster's business model is to make possible the transmission, in the same channel, one HDTV signal in twelve segments with 64 QAM modulation for high quality fixed content and one LDTV (Low Definition TV) signal in one-segment with QPSK or 16-QAM modulation, for mobile applications.

Figure 1 presents a picture sample of the available transmission (left) and reception (right) infrastructure in Brazil

\section{Brazilian Broadcast Industry Scenario}

The analog terrestrial TV operation in Brazil started on September $18^{\text {th }}, 1950$, through an antenna installed on the top of the São Paulo State Bank, in São Paulo. In these past 56 years, the broadcast industry expanded its activities across all of the Brazilian territory, covering all the 5.561 cities in the country [13]. According to governmental studies $91,4 \%$ of all the 55 million households have a TV set.

The Brazilian broadcast industry is vertically integrated, concentrating production, programming and distribution, and it is highly competitive. In São Paulo, for instance, the total number of $26 \mathrm{UHF}$ and VHF channels is all taken. Therefore, an important requirement from the broadcasters point of view is the spectra management as well as the maximization of audio and video quality. With appropriate legal models, the government will be able to permit new broadcast players.

From the population point of view we may suppose the following requirements:

- Better image and sound quality, considering the high density of impulse noise, the degraded infrastructure available in concentrated urban areas and lack of regulatory policies for spectra noise;

- Higher number of channels; considering the poor offer of the local terrestrial programs;

Low cost: considering the asymmetric income distribution, particularly observed in developing countries. 


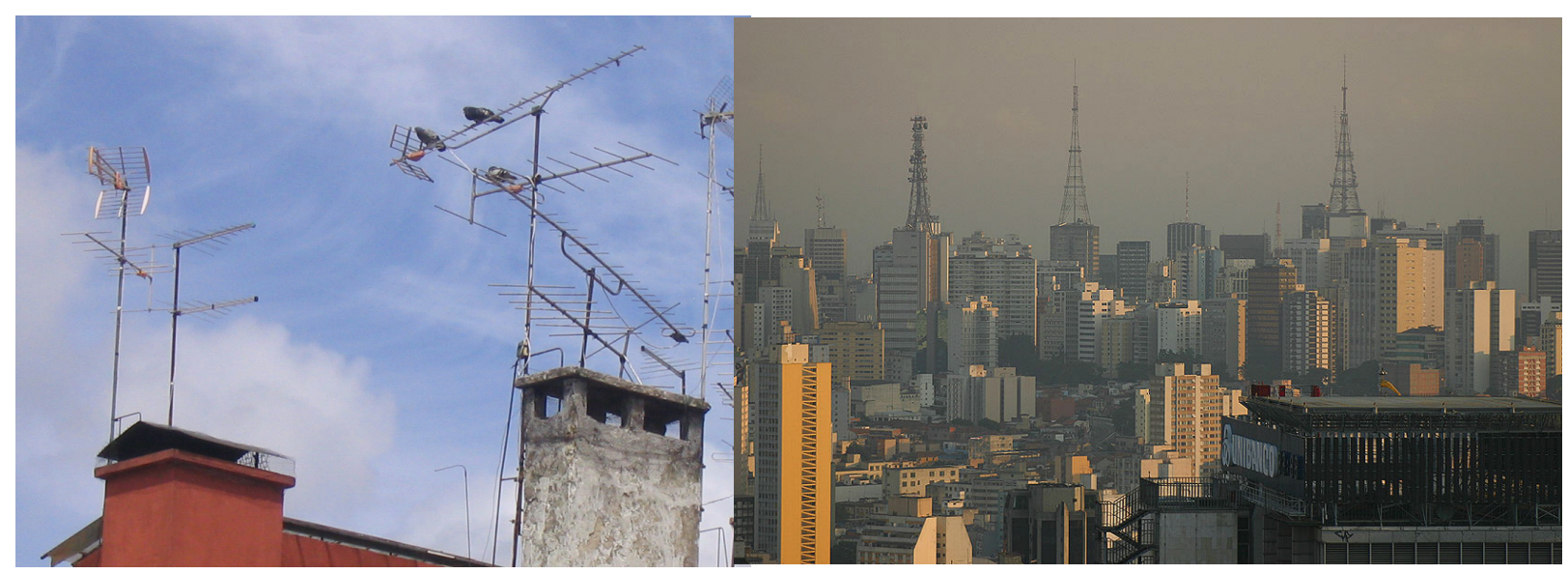

Figure 1 : Transmission (broadcast backbone in Paulista Avenue in São Paulo and Reception infrastructure (antennas on a neighborhood São Paulo vicinity)

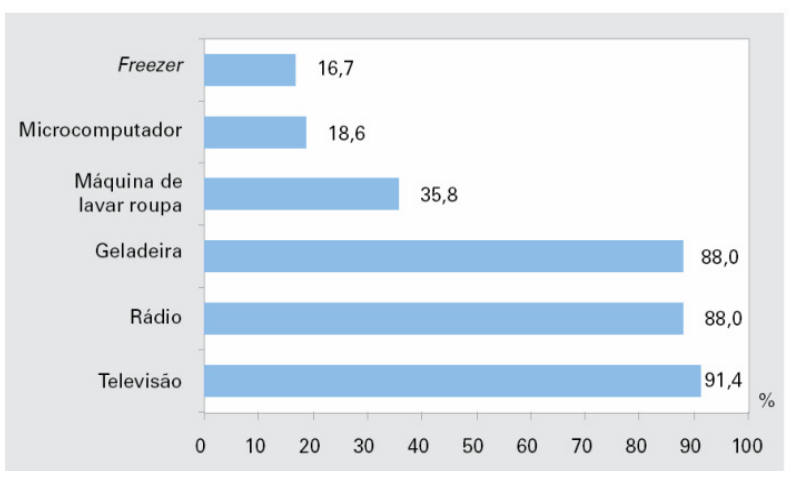

Figure 2: Percentage of Consumer Electronics Devices on Brazilian Households in 2005 (source PNAD 2005)

\section{Access Device Architecture Overview}

The proposed architecture focused on the support of the Brazilian government's decision about the free to air DTV system, adopted to match a set of requirements gathered from the Brazilian scenario and not considering only the emerging services but also the analog TV infrastructure legacy.

Among several identified requirements, we have focused on flexibility, digital inclusion and efficiency. The flexibility requirement addresses the necessity of a wide supply of devices varying on cost, target use and future services. These requirements were managed defining a family of access devices, based on technical and economical analysis, providing features of scalability and proposing a system with the state of the art technologies. Considering the presented requirements we proposed a flexible architecture aiming to fulfill all the requirements on the SBTVD scenario. We describe the architecture from two points of view: layers (Figure 3) and block representation (Figure 4).
The access device is composed by physical components and software components. In a preliminary approach of a layer representation, Figure 3 presents the physical layer and the following software layers: operating system, interfaces for operating system (IOS), resident applications, middleware and broadcast applications.

The hardware layer is based on a printed circuit and the associated semiconductor devices are organized in two main blocks: the Front-End, responsible for radio frequency treatment and the Back-End, responsible for processing the broadcasted digital content (transport stream). This physical layer provides all the system processing features, ranging from general purpose processing functionalities to dedicated processing functions, such as real time multimedia decoding and security.

The subdivision of the software layer into two layers aimed a better reuse in software implementation and also aimed to allow the system interoperability:]. The Operating System API, named IOS (Interface for Operating System), was defined for the first layer and the Middleware API for the second layer.

The software layer is responsible for all user interactive activities as well as the control of the lowlevel hardware layers, and includes the device drivers and operating system. Upon the software layer there is the middleware layer, which provides a communication interface with the interactive applications distributed by broadcasters. The resident applications are provided by manufacturers or embedded in the access device, and may access either by the middleware layer or through the operating system directly without the need of a middleware. 


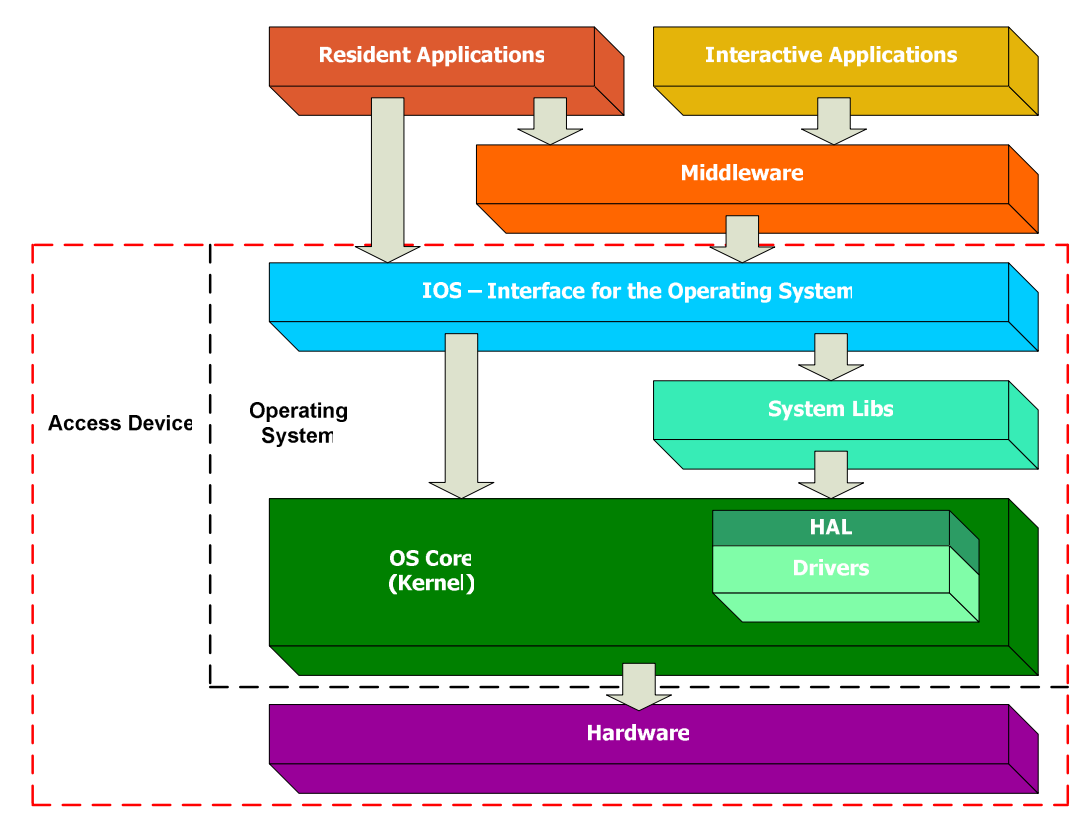

Figure 3: Layer Representation of the Access Device Architecture

In the proposed architecture we introduce the concept of Interface for Operating System (IOS). The IOS encapsulates implementation peculiarities of a given manufacturer, assuring the same software functional behavior across several different platforms. The IOS interface facilitates software developers to concentrate their effort in the middleware and resident application design, since they do not need to loose focus with hardware issues. The access device architecture may also be organized in a block diagram, as presented in Figure 4.

The Front-end block is responsible for the digital TV reception on the SBTVD. It follows the ISDB-T specifications adapted to the Brazilian scenario, changing the channel bandwidth, for example. The Front-end functionalities include channel selection, signal demodulation (which regenerates and distributes the necessary timings for a super frame), a frame and packets through clock regeneration, filtering to eliminate burst signals for carrier synchronization and waveform shaping.

To allow transparent channel navigation among digital and analog channels on simulcast period ${ }^{1}$, the access device architecture adopted a hybrid analogdigital front-end. We use a single tuning stage and two demodulator stages: one for digital ISDB-T demodulation and other for analog PAL-M demodulations.

\footnotetext{
${ }^{1}$ Simulcast period: period of time during simultaneous analog and digital broadcasting, this period is expected 10 year after December $3^{\text {rd }}, 2007$.
}

The transport layer is processed in the demultiplexer block, which considers that the broadcasted contents may contain audio, video and data. The associate standard for the transport layer is the MPEG-2 Systems (ITU-T H.222/ISO/IEC 13818-1). For audio and video (A/V) coding we adopted the MPEG-4 AAC (Advanced Audio Coding) profiles LC and HE v.1, and the MPEG-4 AVC 4.0 (Advanced Video Coding). In Section IV we justify the choice of these multimedia standards.

The A/V decoder block decodes all the possible broadcasted formats, which are 1080 lines with interlaced scan, 720 progressive and 480 both interlaced and progressive scan for video, and 5.1 channels for audio. The legacy of analog TV sets will require an access device capable to down mix the 5.1 Channel audio to stereo sound and capable to re-scale the video format to a 480 interlaced output.

The video processor block is responsible for overlay graphical objects over broadcasted video. This graphical layer is defined by broadcasted applications providing interfaces that allow users to enjoy interactive TV services. The defined formats are EDTV resolution, 720x480 pixels (rectangular format, 0.9 aspect) based on the [ITU-R 601/656] standard, HDTV resolution, 1920x1080 pixels based on ITU-T 709/1120 standard and, since SBTVD considers digital inclusion features, we adopted also the 640x480 resolution profile, for Internet and related applications such as web browsing and email compatibility.

The recommended color depth are RGB 8:8:8, RGBA $4: 4: 4: 4$ and RGBA $8: 8: 8: 8$, also repositioning of $1 / 4$ and $1 / 16$ of the screen in any given screen position. 


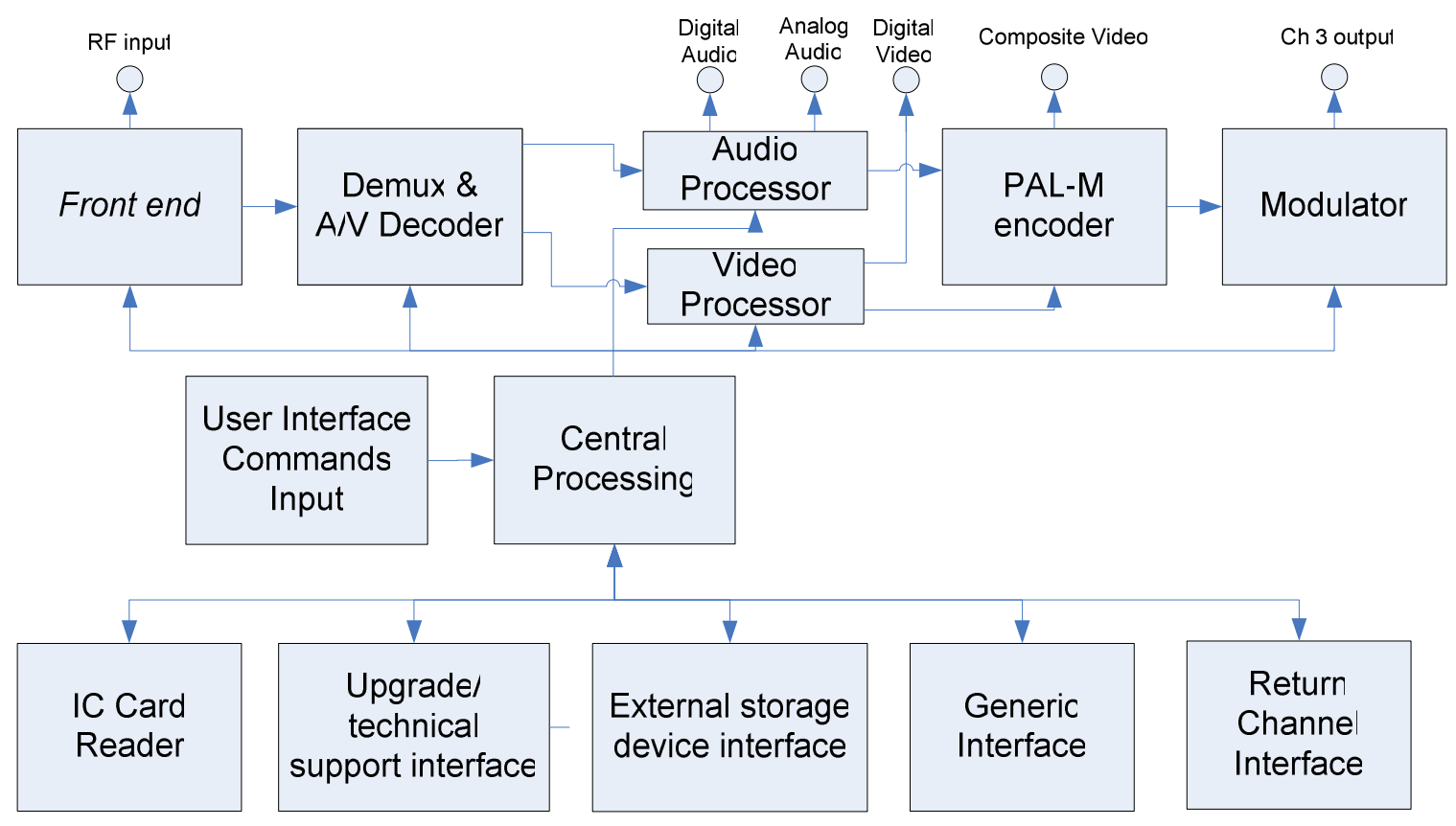

Figure 4: Block Diagram of the Access Device Architecture

The interfaces for standard definition (until 480p) are component video and composite video, with no analog encryption. For security and quality purposes the high definition digital signal can only be output on an HDMI encrypted interface.

The audio processor block is responsible for:

- Mixing sound sources, both synthetic, locally generated, and broadcasted, received from the audio decoder.

- Post-processing functions, such as volume control and equalization, among others;

- Local sound synthesis for the analog and digital audio output stages, DACs and digital audio interfaces, such as S/PDIF.

Typical sound mixing and surround down mixing functions can be digital and/or analog, accomplished through a digital mixer module before the DAC at the output stage, or through analog mixing just after DA conversion. Digital mixing can also take place at the application level.

Post-processing features can also be implemented in digital or analog modules. Advanced features include local synthesis, as well as transcoding functionalities. Transcoders provide a reencoding of the digital sound channels to an alternative digital output format, such as DTS for instance, currently popular in most home-theater platforms.
In this work, we defined as minimum characteristics to be satisfied in terms of audio quality and format:

- Sampling rate: $48 \mathrm{kHz}$;

- Signal-to-Noise Ratio: $70 \mathrm{~dB}$;

- DA spectral resolution: 16 bits;

- Audio file formats: PCM (WAV) and compressed (MP2, MP3, AAC);

- Multichannel support: stereo (2.0) and surround (5.1);

- File formats for synthesis control: MIDI.

Once again concerning the block diagram, the central processing core consists of the CPU itself, system memory, $\mathrm{I} / \mathrm{O}$ and generic controllers. The following picture,

Figure 5, shows the expanded central processing core.

The generic interface block was proposed considering the spatial intra-terminal scalability, that is defined as an interface to permit that users could incorporate to the access terminal extra functionalities and block both in hard and software provided by different manufactures. We recommend an external physical generic interface available in all access devices and among several possibilities we recommend the USB interface. Additional interfaces such as the IEEE1394 Firewire, PCMCIA and Ethernet are recommended as optional interfaces for advanced access devices, under manufacturer's 
criteria. For software scalability and updates we proposed the adoption of external memory drives that can use the generic interface, this mechanism does not exclude the possibility of software updates by the broadcast infrastructure or by the interactive channel.

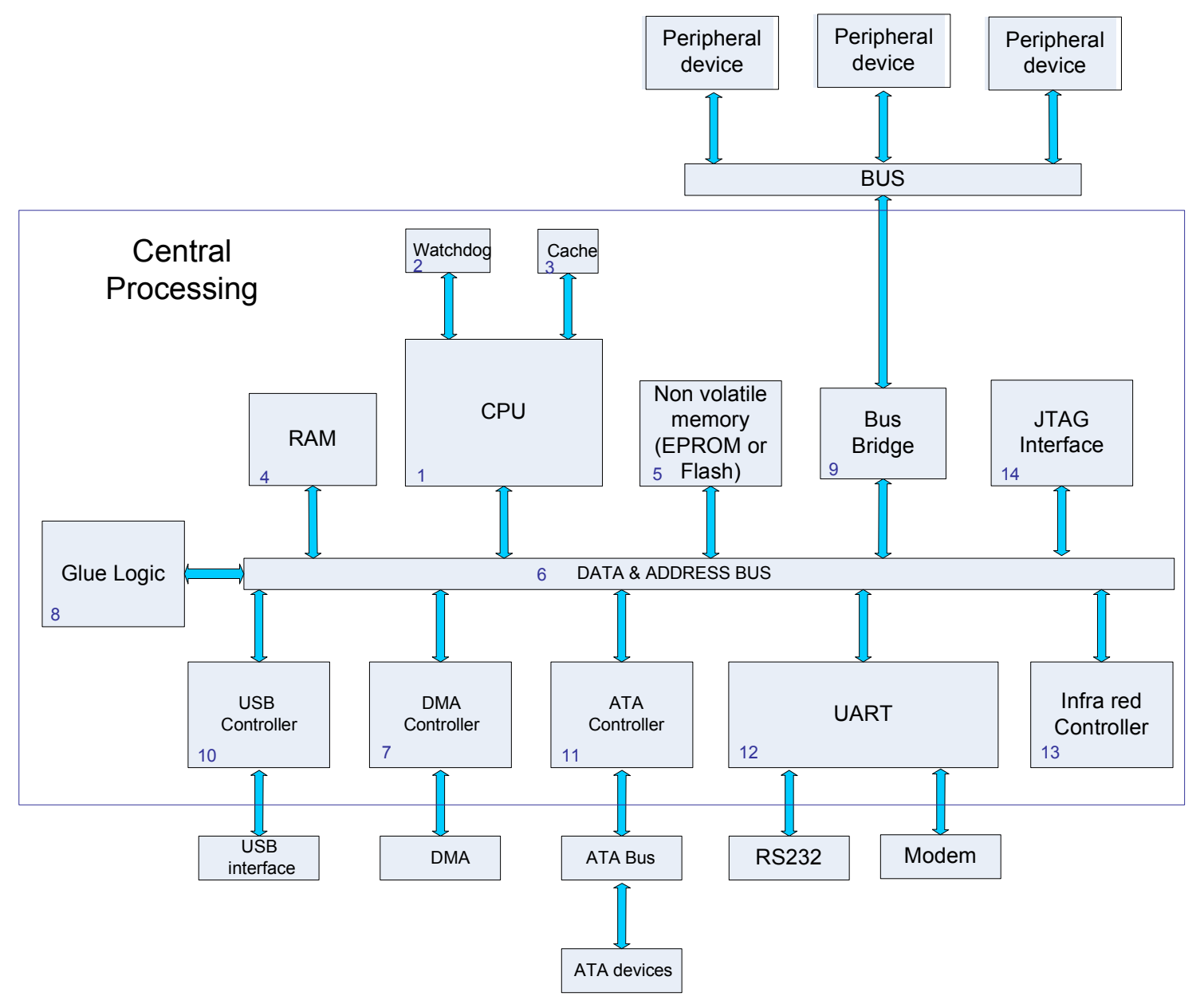

Figure 5: Block Diagram of The Central Processing Core

The mass storage block allows the access device to expand its functionality and store a given content locally [34]. Possible emerging interactive applications are related to video-on-demand services and controls, as fast forward, pause and fast feedback. The generic interface can be used as a mass storage external interface.

The maintenance interface's goal is to verify the functional state of a given access-device allowing the update of low-level software layers such as the device drivers, operating system and security modules. Physically it could be the same interface of the generic interface.

The IC-card reader is proposed to consider emerging interactive services and to establish user authentication. Examples of such applications are related to TV-banking, TV-health and other privacy related services. We recommend IC cards with digital certificates and the adoption of the PKI infrastructure already implemented in Brazil [35].

\section{Functional classification}

Since the architecture is functionally flexible and scalable, one can classify the access device in a family with three main categories, which are particularly relevant from a technical-economic perspective:

- Minimal Cost Access Device: this category considers the simplest and lowest cost access devices, offering the essential audio and video DTV services and local interactivity ([11], [12]); 
- Digital Inclusion Access Device: this category considers the access devices with high interactivity infrastructure such as the return channel, Public Key Infrastructure (PKI) and other governmental requirements;

Aggregate Value Access Device: this category considers the access devices with advanced functionalities demanded by industry and market, such as PVR (Personal Video Recorder) and interactive gaming support.

Table 1 presents mandatory and optional functional requirements for each category above.

\begin{tabular}{|c|c|c|c|}
\hline & Minimal Cost & Digital Inclusion & Aggregate Value \\
\hline $\begin{array}{l}\text { Requiremen } \\
\text { ts }\end{array}$ & $\begin{array}{l}\text { - Conversion of } \\
\text { the digital } \\
\text { signal to } \\
\text { analogical for } \\
\text { the TV input. }\end{array}$ & $\begin{array}{l}\text { - Interface for external } \\
\text { device connection } \\
\text { - Local and remote } \\
\text { interactivity; } \\
\text { - External modem } \\
\text { interface; }\end{array}$ & $\begin{array}{l}\text { All requirements of the } \\
\text { previous families. }\end{array}$ \\
\hline Optional & $\begin{array}{l}\text { - EPG support; } \\
\text { - Maintenance } \\
\text { Interface; } \\
\text { - Local } \\
\text { interactivity. }\end{array}$ & $\begin{array}{l}\text { - Internet and e-mail access } \\
\text { - Conditional Access } \\
\text { interface } \\
\text { - Built-in modem } \\
\text { - IC card interface }\end{array}$ & $\begin{array}{l}\text { - Mass Storage device; } \\
\text { - PVR; } \\
\text { - Convergence with paid TV; } \\
\text { - Communication with other } \\
\text { devices (Ex. PC, DVD, } \\
\text { another Access device, etc); } \\
\text { - Other new functionalities }\end{array}$ \\
\hline
\end{tabular}

Table 1: Access Device Family Categories

\section{OPERATING SYSTEM}

In the past 10 years we observed a significant development of high performance low power microprocessors that can be embedded on consumer electronic devices using $\mathrm{ASIC}^{2}$ technology. This trend based on the development of advanced $90 \mathrm{~nm}, 65 \mathrm{~nm}$, and $45 \mathrm{~nm}$ nano-electronics processes had a direct impact on the DTV receiver industry, making available a range of low cost displays and digital access devices. Current embedded microprocessors targeting the DTV receiver devices have become much more powerful both in multimedia decoding performance and general purpose functionalities such as I/O interfacing, memory and mass storage management, interactivity, media distribution and security.

We decided to give particular attention to the operating system layer in our proposed architecture, since a new generation of DTV ASICs can support complete and advanced operating system environments and since, on the other hand, traditional computer-like devices with already incorporated complete operating systems such as PDAs (Personal Devices Assistants), desktop Personal Computers and laptop computers can also act as DTV access devices.

\footnotetext{
${ }^{2}$ ASIC Application Specific Integrated Circuit
}

The benefit of defining the operating system functionalities' specification as an adaptation layer for the DTV middleware, resident applications and other software issues, is to facilitate the hardware abstraction of the access device for multiple vendor implementations, but also keeping the same essential functionality behavior and allowing software developers to focus on access device final users rather than on hardware issues. The operating system layer can be better understood in Figure 6.

\section{Interface for Operating System IOS}

In order to better define the hardware abstraction layer, gathering and encapsulating related physical components of the access device architecture, we proposed a set of APIs representing each category of functionalities. The whole set of APIs is named IOS (Interface for Operating System). Besides the most used APIs, some other functional developments were done in order to improve system performance (Fast Boot and Operating System Quality of Service), and were also represented in APIs.

The IOS APIs are the following: 
- IOS-BASE: offers access to basic general purpose computing resources such as the CPU, RAM memory management, mass storage devices and system clock;

o IOS-NET: offers access to the network physical layer of the return channel, that can be implemented by several communication technology means such as modem, Ethernet and IEEE 802.11 and IEEE 802.16 wireless technologies;

- IOS-SEC: offers access to security hardware devices such as Smart Card readers, TPM (Trusted Platform Module), and cryptographic algorithms for DRM (Digital Rights Management) and other security related issues;

○ IOS-IOD: offers access to Input/Output Interactive devices with end users, such as the remote controls, keyboard, Joystick, and other I/O ports (USB, RS 232 and IEEE 1394);
O IOS-TV: offers access to dedicated TV hardware resources such as: Front-End Module (tuner, demodulator and channel decoder), the transport stream demultiplexer and to the audio and video decoders;

o IOS-GRA: offers access to graphics and display dedicated hardware such as video controllers and 2D and 3D graphics accelerators;

○ IOS-SND: offers access to sound dedicated processors and hardware, such as the audio controller, audio generator and associated features (mixing, equalizers among others);

○ IOS-PWR: offers access to energy related features through the basic BIOS I/O compatible energy management;

o IOS-QOS: offers access to an additional group of features that have no direct relation to a specific hardware block, but are essential for the reservation of resources like network processing.

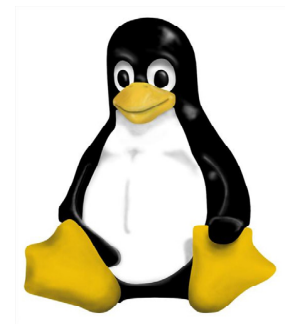

\section{SOTAR - Reference Operating System for the Brazilian DTV Access Device}

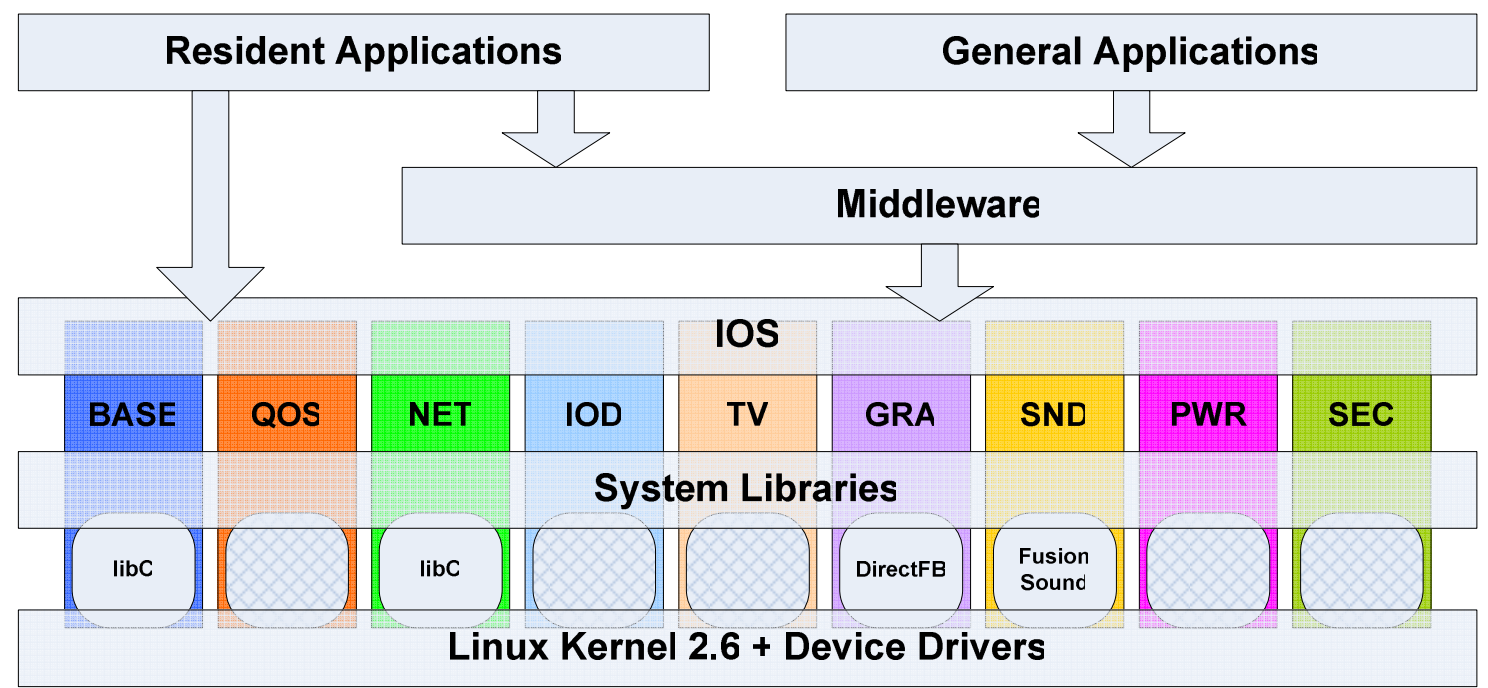

New developments

Figure 6: DTV Proposed Operating System Organization 


\section{AUDIO AND VIDEO CODING FORMATS AND STANDARDS}

The compression technology is key to turn possible to deal with huge sound information quantities. Modern sound formats go far beyond stereo, and DTV is not an exception. It became a necessity and even a commodity to have multichannel programs, and this introduced another class of functional coding: the spatial coding or, more popular, the wide screen video and surround audio [17].

Audio and video in modern television systems are produced, processed, stored, transmitted, recovered and reproduced in a pipeline-like chain as shown in Figure 7. Editing and mastering digital media formats are usually associated with uncompressed data. Metadata can be added to the encoded digital audio and video streams or to chunks of description headers in the bit stream in order to inform decoders how to adequately recover the audio and video payloads. Finally, with different surround modes and alternatives to reproduce the spatial sound or stereo output, access devices may rely on different schemes for final reproduction, for example by decoding completely the sound set and playing all channels through local (analog) outputs, or bypassing a digital stream to another equipment - the home theater so that this final gear decodes and outputs sound channels ready for analog loudspeakers.

The choice of embedding the whole sound decoding engine or implementing part is merely an industrial and market issue, with impact over the final price of the system and also over the sound quality in many practical access devices. It turns out that simultaneous high sound quality reproduction and the capability to satisfy more than 2 channels (surround mode) leads to more expensive terminals, and then incorporating the decoder and player functions to home theaters is very common.

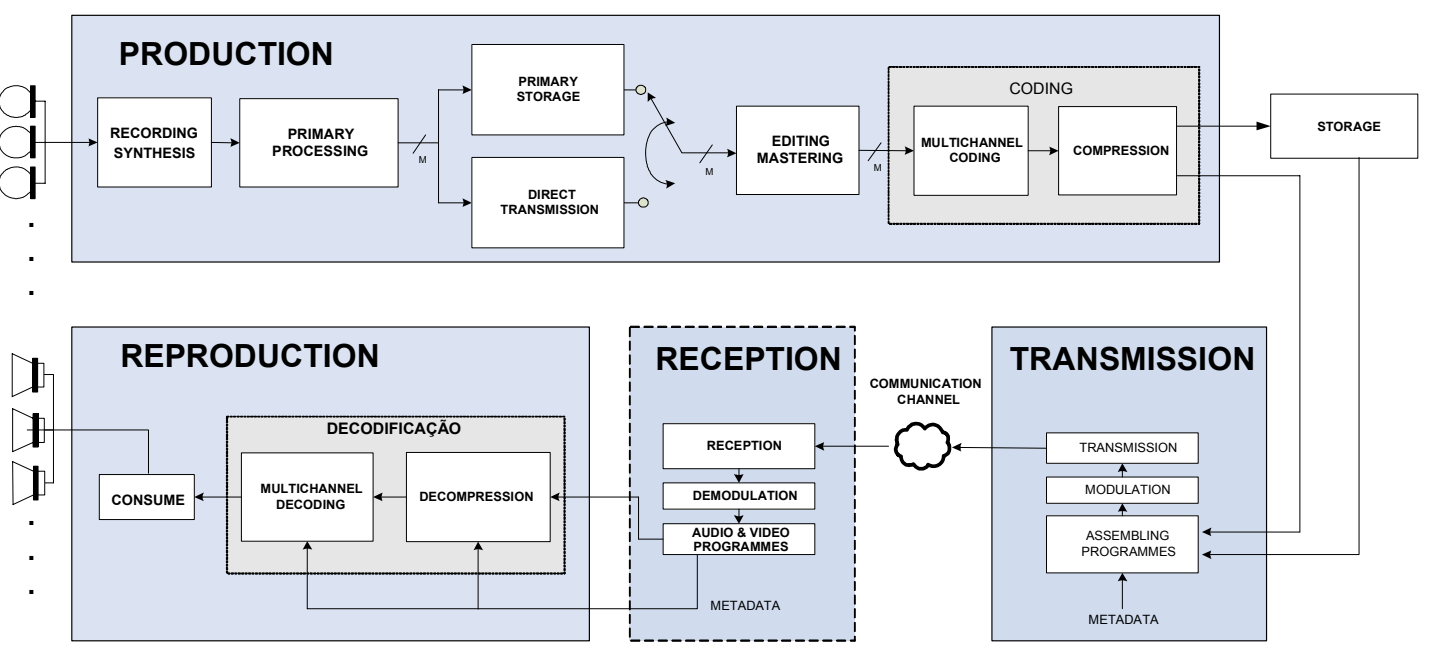

Figure 7: The audio/video chain in DTV: production, transmission, reception, and reproduction

As in 2005 the video coding for digital broadcasting in all the three established DTV systems (ATSC, DVB and ISDB) was the MPEG-2 video standard, and as H.264/AVC was emerging by that time as a natural substitute video coding tool for DTV, both standards (MPEG2 Part 2 and H.264/AVC) were evaluated and considered for adoption in the Brazilian system.

Similar scenario refers to the audio coding tools used in DTV, with the difference that presently there are three standards in use, Dolby AC-3, MPEG-2 Part 3 and MPEG-2 Part 7 (MPEG-2 AAC - Advanced Audio Coding). In the audio domain, four coding standards were evaluated, including MPEG-4 AAC.

Several experimental comparisons showed that H.264/AVC (Advanced Video Coding) and AAC (Advanced
Audio Coding) were in fact indicated as the prominent solutions for the SBTVD, considering not only media quality issues but also an efficient spectral (bandwidth) usage.

The deployment of DTV A/V decoders in large commercial scale has as main challenges the compromise between satisfying the routes of best electronic designs and the observation to novel scientific breakthroughs and technical trends, while keeping compatibility to legacies, specially during transition phases, where both market ends are maturing. State of the art decoders are on a first hand the best solutions to address high quality and least consume of bandwidth, but they also have impact on the manufacture chain, as industrial implementations are not mature enough, and a long integration with other modules of the systems are expected. 


\section{Audio and Video coding}

While MPEG-2 video decoding could be accomplished in real time by most computer and embedded architectures available in 2005, H.264/AVC was not so easily handled. When considering high definition video (HD) with H.264 coding, the architecture requirements, in terms of computer power and bus throughput, were even harder to attend.

The industry has been signaling to provide new technologies that would shortly attend H.264 HD requirements, as indeed occurred during 2006. With this fact in mind, together with the cost forecast presented later in this paper, it was reasonable to propose the adoption of H.264 as the unique video-coding standard for the SBTVD.

Table 2: possible sound services, programs and surround modes

\begin{tabular}{|c|c|c|}
\hline Services & $\begin{array}{l}\text { Sound } \\
\text { programs }\end{array}$ & $\begin{array}{l}\text { Modes (channel } \\
\text { configuration) }\end{array}$ \\
\hline $\begin{array}{l}\text { Main video } \\
\text { sound program }\end{array}$ & $\begin{array}{l}\text { Mono } \\
\text { Stereo }\end{array}$ & $\begin{array}{l}1(1.0) \\
2 \text { channels }(2.0)\end{array}$ \\
\hline $\begin{array}{l}\text { Audio } \\
\text { description } \\
\text { Secondary } \\
\text { language } \\
\text { Side audio } \\
\text { (music, etc.) }\end{array}$ & $\begin{array}{l}\text { Surround } \\
\text { (spatial sound) }\end{array}$ & $\begin{array}{l}2.1 \text { channels } \\
\text { (plus LFE/subwoofer) } \\
\text { alternative modes } \\
(3.0,4.0,4.1 \text {, etc.) }\end{array}$ \\
\hline $\begin{array}{l}\text { Separate voice } \\
\text { and music } \\
\text { Additional } \\
\text { sound services }\end{array}$ & $\begin{array}{l}\text { Simultaneous } \\
\text { stereo and } \\
\text { surround }\end{array}$ & $\begin{array}{l}5.1 \text { (6 channels }) \\
7.1 \text { (8 channels })\end{array}$ \\
\hline $\begin{array}{l}\text { Audiovisual } \\
\text { realism } \\
\text { enhancement } \\
\text { Sound synthesis } \\
\text { (terminal) } \\
\text { 2D/3D sound } \\
\text { scene capability }\end{array}$ & $\begin{array}{l}\text { Concurrent } \\
\text { multiform at } \\
\text { delivery } \\
\text { (Surround } \\
\text { formats/codecs) }\end{array}$ & $\begin{array}{l}\text { Advanced } n . m \text { modes } \\
(\mathrm{n}+\mathrm{m} \text { channels }) \\
\text { mixed modes } \\
(2.0+5.1 \text {, etc. })\end{array}$ \\
\hline
\end{tabular}

In the case of audio, several aspects are relevant when defining the coding strategy and formats for DTV. A rule of thumb is observing present and future requirements, such as sound quality and service diversity for the Brazilian scenario. Brazil's rich sound content production, the creativity freedom and innovation in delivering more than one sound program (e.g. simple stereo, full surround, fixed and mobile reception) push for a flexible and scalable coding strategy to achieve simultaneous delivery of audio services (e.g. stereo, surround 5.1, second language, auxiliary data, side channels, and audio description).

More bit-streams and channel configurations are good resources to accommodate a lot of new services, surround modes and even advanced options for sound field encoding in the future. Table 2 shows typical sound services, program and surround modes envisaged for the sound sub-system in DTV

\section{Audio coding formats and standards}

There are several standards and formats for audio coding and compression available, and choosing one approach for a mass telecommunication system requires a compromise among many issues, such as minimum sound acceptable quality, channel bandwidth availability, quality of service, requested computational cost, robustness, implementation complexity, easy content production, long-life cycle promises, and licensing costs.

Loss less codecs, in spite of their superior sound quality, do not satisfy the compression rates required for digital television and radio services. Perceptual codecs are much more indicated for this application. A sound codec, capable of addressing with similar quality a large variety of sound types, is also required for television purposes, once that different codecs usually exhibit different quality (for the same bit rate) compressing different types of sound.

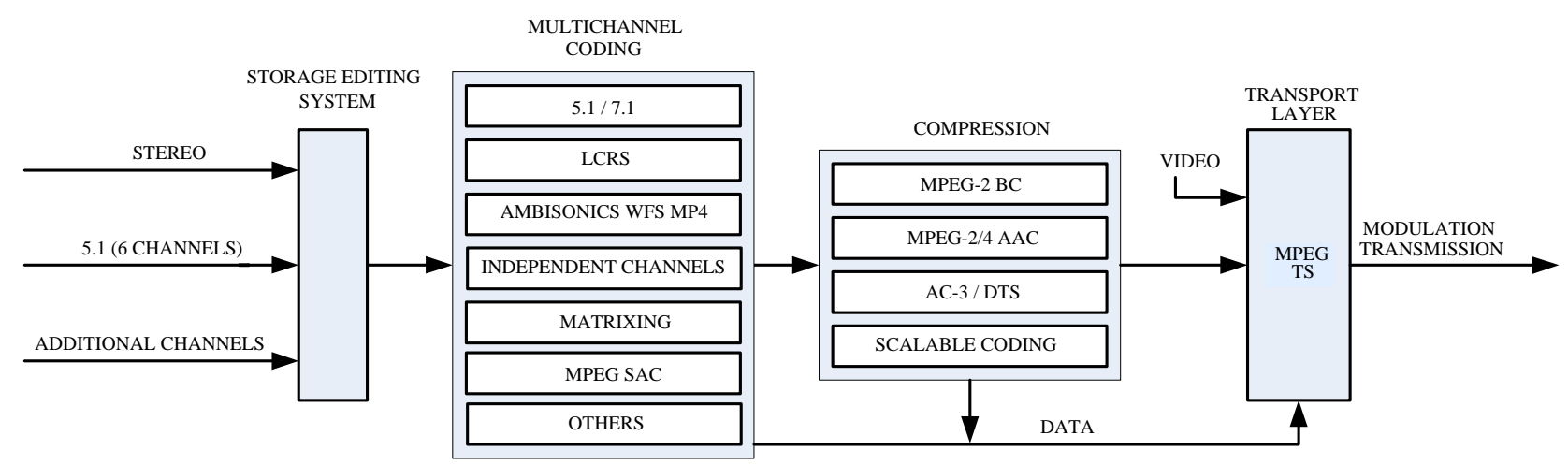

Figure 8: Audio encoding stages for delivery 
Figure 8 shows an overview of the successive stages in which audio information is encoded and packed for DTV delivery, and Figure 9 shows the reception and decoding stages performed at the access terminal. The adherence to internationally recognized and widely adopted standards was a main force driving the choice. The MPEG-2 BC (Backward Compatible), MPEG-2/4 AAC, Dolby AC-3 and DTS are prospective coding tools both for surround (spatial) coding and for compression, and are found in the major multimedia and telecommunication standards in use today. Based on their added value, wide adoption (including in most DTV standards) and technical qualities, they were considered candidates for the SBTVD audio coding/decoding architecture.

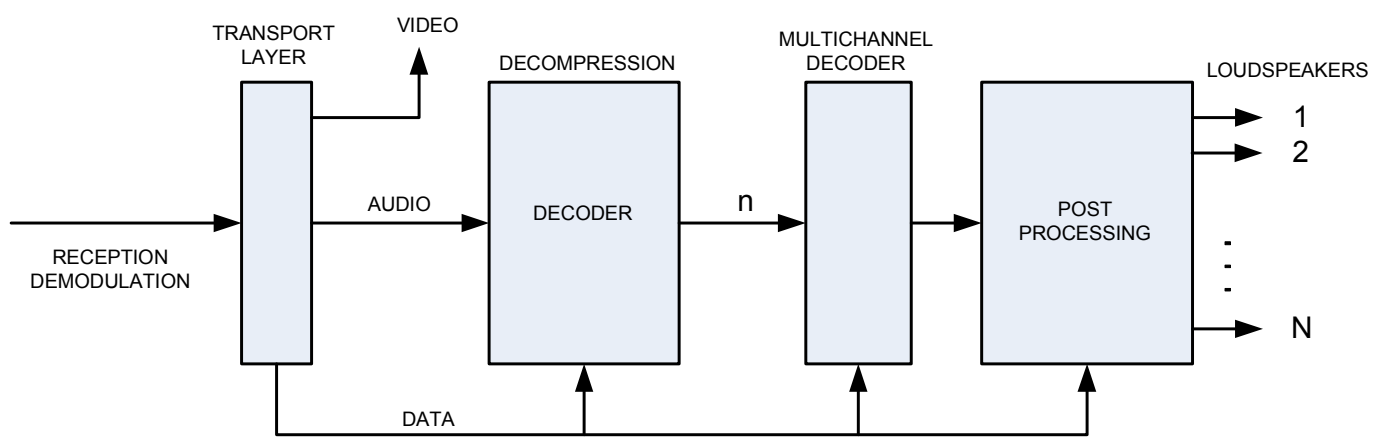

Figure 9: Audio reception and decoding stages at the access terminal

However, while they all can be used for audio coding in DTV, they exhibit differences in several attributes such as: sound quality versus compression rate (performance issues), and proprietary versus open/free implementations (economical and reliability issues).
These naturally emerge from their different coding approaches, history and generations.

Table 3 shows how main codecs perform requiring distinct bit rates to deliver the same subjective quality.

Table 3: Comparing bit rates for the same perceived quality

\begin{tabular}{|l|c|c|c|c|c|}
\hline \multicolumn{1}{|c|}{ (In kbps) } & MPEG-1 Layer & $\begin{array}{c}\text { AC-3 } \\
\text { (Dolby) }\end{array}$ & $\begin{array}{c}\text { AAC- } \\
\text { LC }^{1}\end{array}$ & v.1 $^{\text {AAC-HE }}$ & AAC-HE \\
\hline Stereo & 192 & 192 & 128 & 64 & 32 \\
\hline Multichannel & - & 384 & 320 & 160 & - \\
\hline
\end{tabular}

Based on several comparative analysis between these codecs taking all above attributes into consideration, the MPEG-4 AAC was considered the most preeminent candidate from all, and assigned for official adoption in SBTVD, for it shows better performance and ranks higher in almost all requirements, in spite of its adoption in DTV scale is not yet established. One important consideration in the decision for AAC was due to its adoption in the ISDB system. However, ISDB adopted the MPEG-2 AAC and for the SBTVD the newest version of MPEG-4 AAC was adopted, and it is back compatible with MPEG-2 AAC. MPEG-4 AAC offers new functionalities, tools and a more elaborate framework to describe profiles, accommodate innovations, and to be more conformant to new MPEG transport mechanisms.

We analyzed AAC implementations based on combinations of tools/profiles in order to infer what combinations were more advantageous for the SBTVD in terms of cost/benefit and sound quality [18] AAC-LC (Low Complexity), LTP (Long Term Prediction) and HE (High Efficiency, v.1) were tested. We also considered in the study comparisons between different codecs (MP3, Ogg Vorbis, and AAC) and proprietary versus open/free implementations, targeting mainly their performance. Results showed that AAC-LC and HE profiles deliver excellent audio quality, particularly above $128 \mathrm{kbps}$, and 
that LTP tool usage did not exhibited neither perceptual nor computational advantages.

The MPEG-4 AAC codec encompasses a family of audio coding algorithms, extensions and profiles which can be selected and associated in a specific implementation to satisfy different quality and computational requirements or restrictions [20]. It presents several advantages for DTV usage over older codecs, such as superior quality in lower bit rates, flat frequency response curves, computational efficiency, larger channel capacity (up to 48), robustness, wide adoption in several telecommunication markets, stateof-the-art tools and alignment with modern trends towards high definition audio.

An AAC decoder is basically composed of a bit-stream payload extractor, which will parse the bit stream and recover control and audio data information for subsequent spectral processing and time-domain processing. Fine filter banks and block switching are employed for time-frequency transforms. During encoding, prediction and other tools are used in the spectral domain to eliminate redundancies, with a psychoacoustics block. Psychoacoustics will infer the quantization rules for each audio frame, thanks to known masking properties of the auditory system. While some tools are obligatory in any implementation (e.g. noiseless coding, TNS - temporal noise shaping, etc.) some will be only required to build specific AAC profiles (e.g. LTP long term prediction).

Figure 10 shows a possible implementation for the MPEG-4 AAC block decoder in DTV access devices.

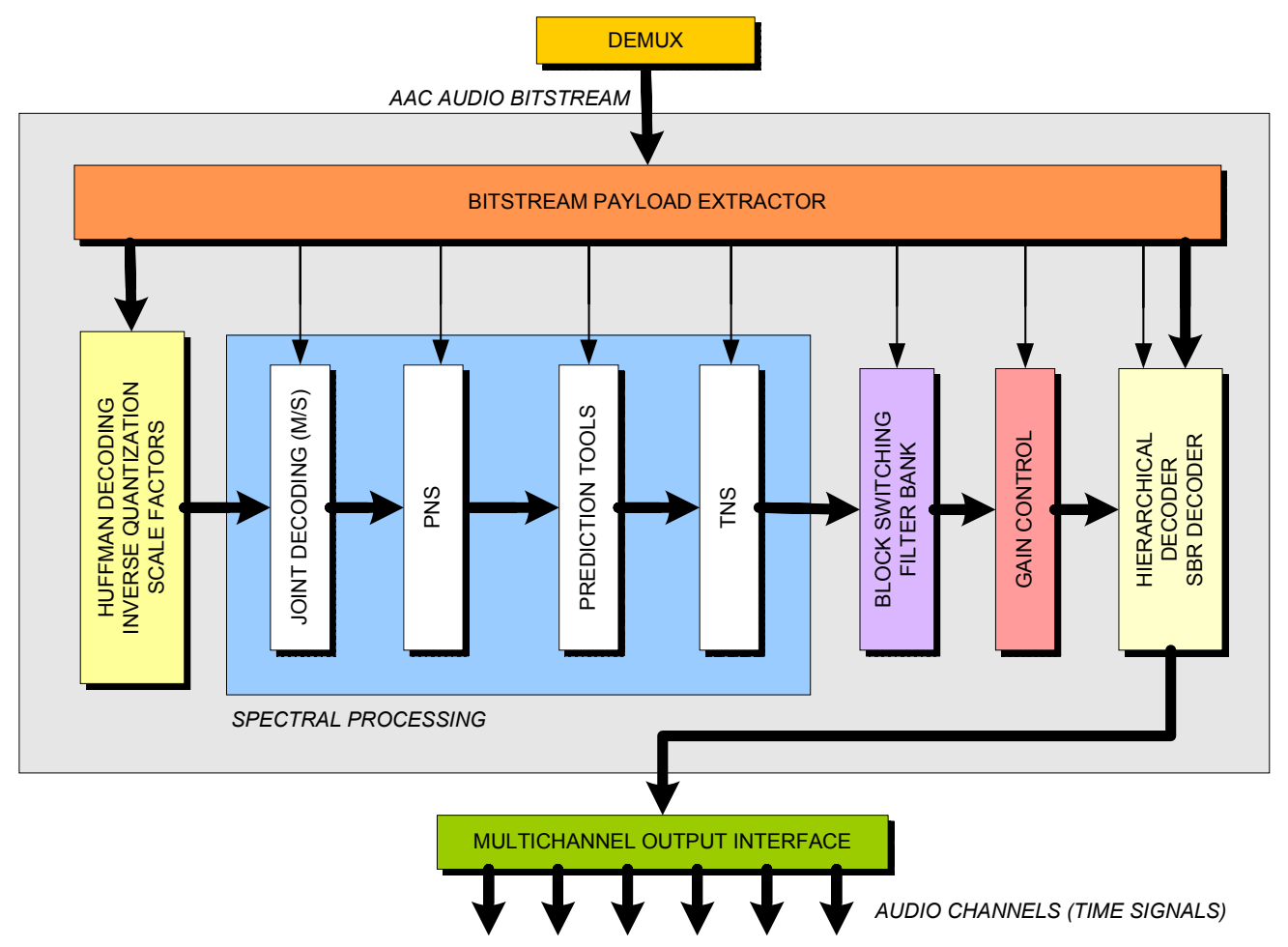

Figure 10: MPEG-4 AAC Block Decoder

The MPEG-4 AAC is a highly compressive and high quality MPEG codec, which incorporates many new features and tools over the previous MPEG-2 audio codec, such as the SBR (Spectral Band Replication) and PS (Parametric Stereo). An SBR tool is required to implement the HE v.1 (High Efficiency, version 1) profile. In the SBTVD, both MPEG-4 AAC LC (low complexity) and HE v.1 (High Efficiency) profiles are indicated for fixed reception, and HE v.1 is indicated for mobile services.
New codecs require much more processing power than current MPEG-2-based ones. This can be supplied by different computational approaches, including mixed hardware and software, and the chosen implementation technology will impact the final terminal cost. Considering a given set of alternatives with yet unknown performance, the lead-time to settle codec implementation standards in the market is not well estimated now. Risks and difficulties in implantation phases may arise also during the transition from past to 
novel production standards, while market content production is very oriented to present standards. This includes the transcoding challenges to face Dolby and DTS 5.1 legacy, but also the opportunities to open new markets for surround production for AAC 5.1 and more channels, due to advanced proposals under development and tests in Japan (e.g. 22.2 multichannel modes).

Another challenge for the SBTVD has been the introduction of new features beyond the ISDB base standard to accommodate the new AAC profiles and desired audio services. The experience to gather consensus among players and main driving forces requires time and efforts to address several technical open questions, such as new transport and signaling mechanisms for MPEG-4 Audio.

\section{USABILITY AND USER INTERFACE CONSISTENCY}

Digital TV allows several new uses for the television. The spectator can become a user and choose a particular camera angle, participate on a poll or play a game. Even beyond that, interactive DTV (iDTV) may become an access point to public services, education, shopping, and many other uses.

An analysis of iDTV applications from many different countries [20], [21], [25], [27], [28], shows that usability is a recurrent problem and in some cases these problems become the impeditive factor that prevents iDTV from reaching its true potential. As Freeman and Lessiter [25] say "The potential benefits that digital TV can bring to those sections of society who currently lack access to interactive information services are unlikely to be realized if digital TV equipment and services are not easy to use, and perceived as such".

\section{Usability and iDTV}

From DVD players to home security systems, several articles present [29], [33] that many consumer electronics have a low level of usability, mainly due to lack of standards, replication of functionalities and excessive complexity of the systems.

That is also the case with iDTV. In a study of the perceived easy of use in the UK, iDTV was considered to be more difficult than a computer or a car [23]. Another study [28] reveals usability problems from the remote control to the graphical user interface from enhanced TV (eTV) programs and Electronic Programming Guides (EPG). In Portugal the difficulty of use was one of the major reasons that prevented users from trying the new services available on iDTV [31] while in Sweden [31] studies demonstrate how the lack of standardization of the remote control across access devices causes usability problems [27].

Considering that the user mostly sees TV as an activity of relaxation and entertainment, a very important fact to consider is that the simple supposition that an interface is difficult to use, or that one has to learn how to use it, might be enough to prevent the user from even trying it [24].

\section{Consistency on User Interfaces}

Consistency is a fundamental attribute in the design of usable interfaces [22], [30], [32] allowing the user to transfer knowledge between situations. By using a system with a consistent interface, the user builds a coherent model of the interface as a whole and is able to use most of the system based on a small number of universal rules. If the interface is not consistent, the user has to learn context specific rules and can never predict the system behavior.

Authors such as Nielsen [30] analyze the many benefits of consistency, both to the user as well as to software developers and equipment manufacturers. From the user's perspective, consistency directly improves easy of learning, easy of use and prevents errors [30] and in an indirect manner: "The smaller number of error and shorter learning time again lead to improved user satisfaction with the system and fewer frustrations with systems which the user cannot use. Finally, consistency strengthens users' expectations with respect to being able to use new software, leading to feelings of mastery and self-confidence." [30].

It is interesting to note that in applications related to relaxation and entertainment, as it is the case with iDTV, subjective satisfaction can be more important than performance metrics, like time and number of clicks required to task completion [30].

\section{Consistency on iDTV User Interfaces}

Our studies during the SBTVD project demonstrated that the lack of consistency is a very common problem [20], [28] and that it has a major negative impact on iDTV user interfaces, especially for users with lower literacy, elderly and users with disabilities [28].

As Gawlinski [26] pictures: "In an ideal world, all interactive applications would use the same navigation model. Viewers would then not have to go through a learning process every time they use a new interactive television service. Unfortunately, in the United Kingdom, although several industry bodies have tried, there's very little agreement on what a consistent navigation model for interactive television should be." 
One of the causes of this inconsistency is that different actors produce the different parts of the interface. The remote control and the basic graphical interface are usually made by the access device manufacturer, the interface for the different iDTV programs are made by various teams that are responsible for producing the content and iDTV services (like a transaction service) are made by software development companies. To the end user however, all these interfaces are perceived as one experience. While they might be consistent when considered separately, to the user they might appear as a large collection of unrelated screens, on-screen buttons and remote control keys, without any coordination among them.

As one of the main conclusions of their work, Klein, Karger e Sinclair [28] emphasize the need for a unified approach for the design of iDTV interfaces, one that considers all of the interfaces that the user comes across and the consistency between them.

\section{A Generic User Interface Model for Interactive TV}

There are several approaches to obtain consistency on user interfaces. Considering that iDTV is an open environment (there's no centralized control) still evolving on a very fast pace, models are a good way to promote consistency. When developing new applications, developers can refer to these models as references to how the interface should behave and thus consistency is obtained [30].

One of the results of our work during the SBTVD is the $\mathrm{C}^{\mathrm{C}}$ proposition of an integrated interface, which focuses on three aspects: a navigation map, the minimum remote and a navigation model. The navigation map is the taxonomy of the system, the minimum remote is a set of keys that should be universally available to the user and the navigation model presents a consistent and extensible mechanism for navigation in iDTV applications.

\section{TECHNICAL-ECONOMIC ANALYSIS}

A technical-economic analysis was developed to understand and guarantee the low cost requirements related to digital inclusion and other relevant issues for the massive DTV deployment in developing countries [11], [12]. The early adoption of state-of-art technology in the access device, such as the HDTV MPEG4 multimedia coding, can imply on a higher cost for the initial deployment phase, however on the long term the possible cost of technological legacies could be reduced or eliminated. In the other hand, the adoption of newer technologies for the access device can increase its scalability for new functionalities adding aggregate value and offering more attractive products for the population in general.

The technical-economic analysis is an essential tool to evaluate the relevance of access device architecture and its implications on other parts of the broadcast infrastructure such as the spectra management, convergence with telecommunication infrastructure and incorporation of emerging interactive services. Our technical-economic analysis methodology considered two perspectives:

1. The evaluation of technology related options and its associated standards targeting the access device itself;

2. The evaluation of the proposed architecture and its implications on the whole broadcast infrastructure;

Considering the technical options, the following essential modules of the architecture are cost dominant:

- The multimedia coding techniques and standards such as MPEG-2 and MPEG-4;

- The software layer, with an emphasis on operating system and middleware issues;

- Display resolution mainly the SDTV (Standard Definition) and HDTV (High Definition) options.

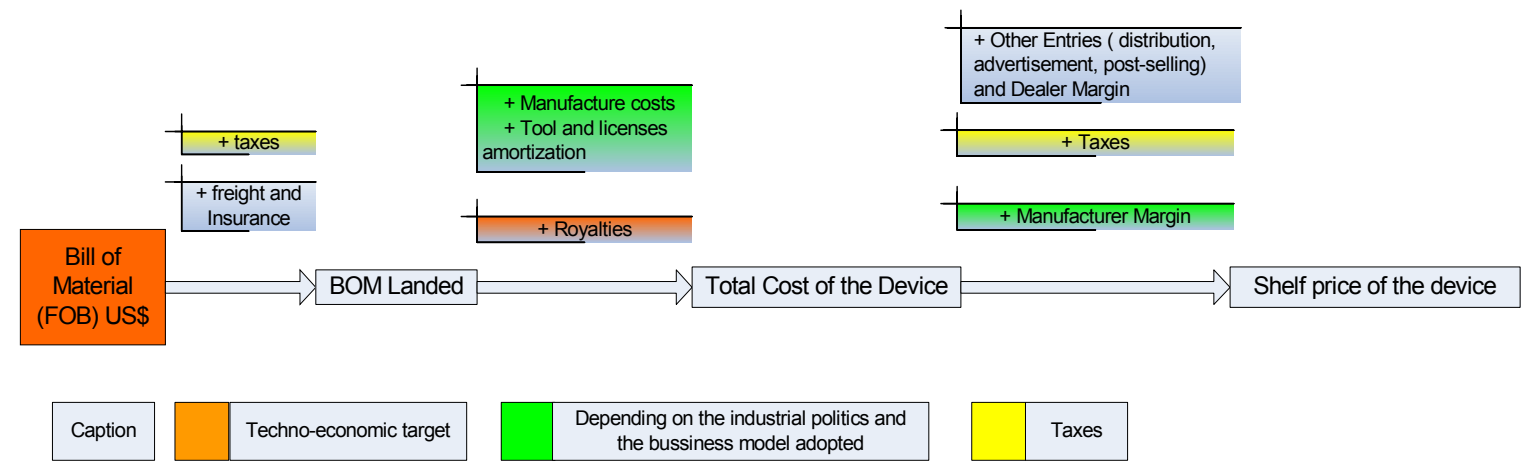

Figure 11: Access Device Price forming Chart Considered in the Technical-Economic Analysis

Figure 11 illustrates main contributors considered in the final access device price forming. The first step to estimate the final cost of each access device family is to forecast local demands. Based on it we have approached several 
local and worldwide access device manufacturers in order to build a Bill-Of-Material (BOM) cost chart for each family category, then we applied the applicable values of the whole Brazilian industry chain to establish the consumer price. These values are presented below.

\section{Demand Forecast}

The demand forecast was evaluated using the historical analogy approach, comparing a temporal selling series of similar consumer electronics devices with the DTV access device. We started our analysis comparing cell-phones sales provided by the Brazilian Telecommunications Agency [13] and the total sales of analog color TVs, provided by the ABINNE (Brazilian Association of Electronics and Electrical Industry), in the past 13 years [14].

Upon this selling series we applied the Bass Model [15] to guess the demand curve. The model parameters are: cell phones $\left(\mathrm{m}=67,5 \times 10^{6}, \mathrm{p}=0,01481\right.$ and $\left.\mathrm{q}=2,025\right)$ and color TVs $\left(\mathrm{m}=55 \times 10^{6}, \mathrm{p}=0,01818\right.$ and $\left.\mathrm{q}=0,55\right)$. The obtained curves are plotted in Figure 12.
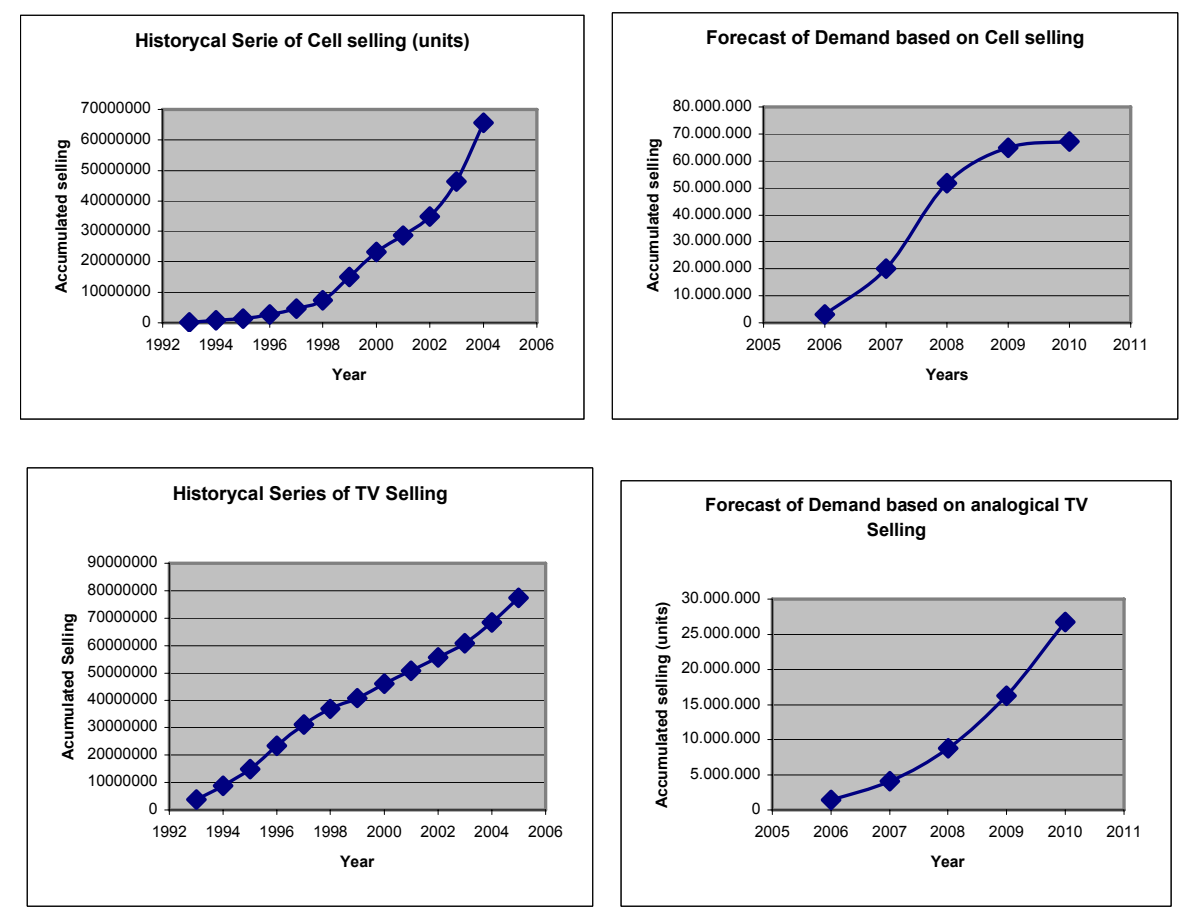

Figure 12: Forecast of Demand Plots Estimated from the BASS Model

From the curves presented we concluded that the Color TV analogy is pessimistic while the mobile phone analogy is optimistic. Our conclusion is that the access device will have a forecast demand more optimistic approximated to the mobile phone, reaching cumulative sales in 5 years to 65 million access devices.
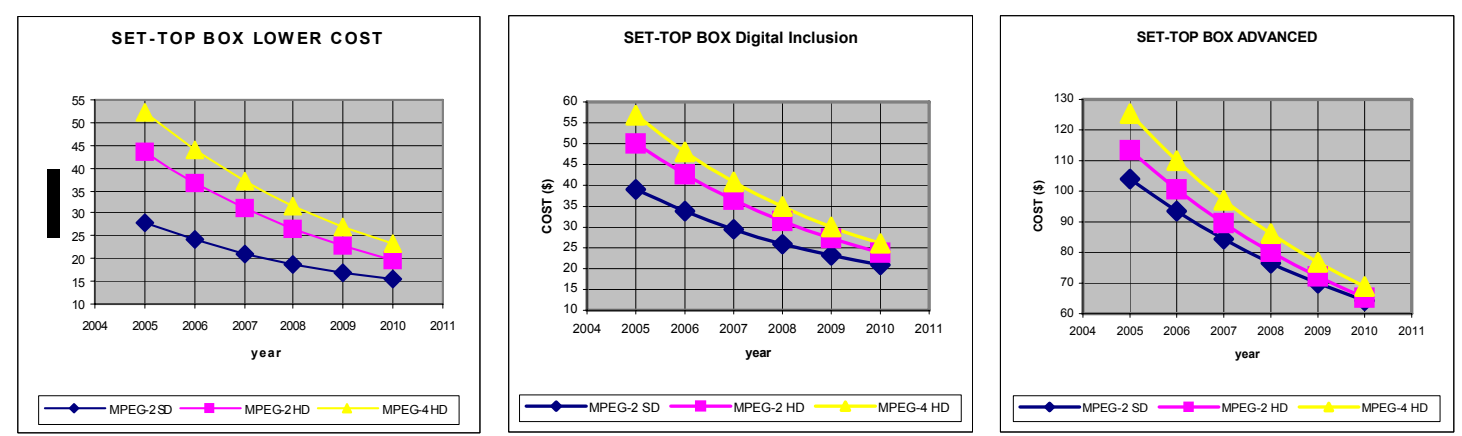

Figure 13: Bill of Material Cost Forecast for the Access Device Family Categories 


\section{Bill of Material Cost and Final Price Forecasts}

We calculated the expected bill of materials cost forecast of each access device family member, based on the BOM of commercial access devices provided by industry, considering three technological options: for interactive access devices: SDTV MPEG-2, HDTV MPEG-2, HDTV MPEG-4. We did also a cost decay estimation based on costs decays provided by industry: according to the following empirical rules:

- State of the art semiconductor components: $20 \%$ decay year;

- Commodity semiconductor components: $10 \%$ year;

- Low value items, plastic, passive components: 5\%/year;
By applying the above rules, we could estimate a BOM forecast, presented in Figure 13.

The final price of the access terminal for the three different categories in this context is presented in Table 4. Based on the technical-economic analysis we decided to adopt the HDTV MPEG-4 (H.264) in our architecture and also recommend it to the SBTVD Reference Model. The main conclusion is that, in the next 5 years, MPEG- 2 and MPEG-4 as well as SDTV and HDTV value differences both in the BOM cost and user price will be irrelevant compared with the gains on spectra management, audio and video quality and support for emergent services.

Table 4: Access Device Price in 2005 and 2010 projection

\begin{tabular}{|c|c|c|c|c|}
\hline \multicolumn{2}{|c|}{ Access Device } & $\mathbf{2 0 0 5}$ & $\mathbf{2 0 1 0}$ & Cost Decay (\%) \\
\hline \multirow{3}{*}{ Low Cost Family } & MPEG-2 SD & $\$ 123,29$ & $\$ 75,50$ & 38,76 \\
\cline { 2 - 5 } & MPEG-2 HD & $\$ 185,25$ & $\$ 92,20$ & 50,23 \\
\cline { 2 - 5 } & MPEG-4 HD & $\$ 238,79$ & $\$ 109,75$ & 54,04 \\
\hline \multirow{3}{*}{ Digital Inclusion Family } & MPEG-2 SD & $\$ 167,80$ & $\$ 96,55$ & 42,46 \\
\cline { 2 - 5 } & MPEG-2 HD & $\$ 211,01$ & $\$ 108,12$ & 48,76 \\
\cline { 2 - 5 } & MPEG-4 HD & $\$ 258,59$ & $\$ 121,24$ & 53,11 \\
\hline \multirow{3}{*}{ Added Value Family } & MPEG-2 SD & $\$ 422,54$ & $\$ 266,57$ & 36,91 \\
\cline { 2 - 5 } & MPEG-2 HD & $\$ 459,40$ & $\$ 270,17$ & 41,19 \\
\cline { 2 - 5 } & MPEG-4 HD & $\$ 505,22$ & $\$ 283,30$ & 43,93 \\
\hline
\end{tabular}

\section{EXPERIMENTAL EVALUATION}

For the experimental evaluation we implemented the access device architecture module by module. Such approach considered the flexibility of building prototypes with different manufacturer technologies and two different implementation strategies: the distributed one and the embedded one. For the central processing block we selected two totally different CPUs provided by the ST Microelectronics for the embedded implementation strategy and by Intel for the distributed implementation strategy.

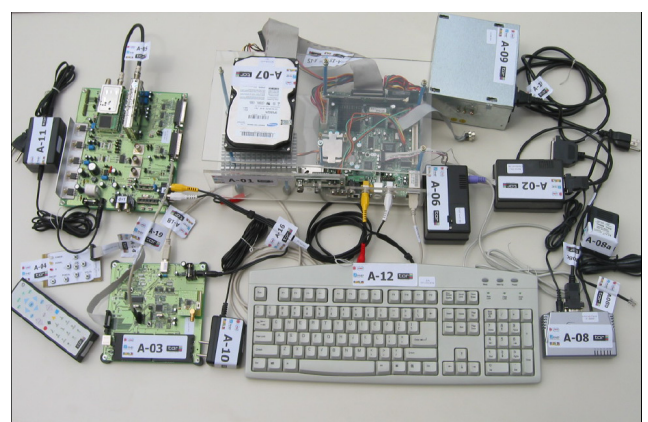

Figure 14: Experimental Implementation of an Access Device
The video decoding block was totally encapsulated in the architecture, and for each platform we evaluated two different video decoding technologies, theMPEG-2 SDTV and MPEG-4 AVC HDTV. In both cases the IOS completely encapsulated the specific implementation and its coding issues guaranteeing the same functional behavior of the access device for final users. Figure 14 presents the implementation setup based on Intel semiconductor components.

Table 5 shows prototype implementation details for each reference CPU technology.

\section{CONCLUSION AND FUTURE WORK}

The definition of access device architectures is an intensive engineering task that focuses on final users, considering an analog to digital TV infrastructure transition. On short term, this approach will reduce the creation of legacies based on technical mistakes related to commercial and political pressures during the transition decision process. The addressing of relevant issues such as the technical-economic analysis and UI consistency evaluation 
is important for long term dynamics of the transition, particularly considering the adoption of state-of-art technologies, as well as the introduction of emerging interactive digital broadcast services.

Since July $29^{\text {th }}, 2006$, this work has been providing subsidies to the standardization of several aspects of the proposed architecture for the SBTVD Forum established by the 5820 Presidential Act. At the same time, further technical consolidation of the proposed prototypes is under development, aiming to have robust access devices for medium scale trials. The forecasts proposed by the technical-economical analysis are been traced with inputs from companies, which are currently developing their products aiming at DTV commercial deployment in Brazil by December 2007. Currently the operating system built is being optimized targeting embedded access devices.

Table 5: Prototype Implementation (per platform)

\begin{tabular}{|c|c|c|}
\hline & Intel & ST \\
\hline \multirow{2}{*}{ Operating System } & Kernel: Linux & Kernel: Linux \\
\hline & Distribution: GoboLinux & Distribution: GoboLinux \\
\hline Front-end & ISDB-T ALPS + DVB-SPI/PCI adaptor & ISDB-T ALPS + DVB-SPI/PCI adaptor \\
\hline \multirow{6}{*}{ Central processing } & Intel Celeron processor $1,2 \mathrm{GHz}$ & SH40 processor \\
\hline & Graphics and memory controller Intel 82815 & \multirow{3}{*}{ ST7100i } \\
\hline & Interfaces controller Intel 82801 & \\
\hline & Firmware controller Intel 82802 & \\
\hline & 256MB SDRAM & 256MB SDRAM \\
\hline & 32MB IDE FLASH & 32MB IDE FLASH \\
\hline Demux & VLC and software expansions & VLC and software expansions \\
\hline Áudio decoder & VLC & Embedded + STAPI \\
\hline Video decoder & VLC + hardware tools for acceleration & Embedded + STAPI \\
\hline Video processor & 82815 + Direct Frame Buffer + SDL lib & Embedded + Direct Frame Buffer over STAPI \\
\hline Áudio processor & $\mathrm{ALSA}+\mathrm{AC} 97$ & Embedded + STAPI \\
\hline User interface input & $\begin{array}{l}\text { User Interface Bridge - remote controller, } \\
\text { wireless keyboard }\end{array}$ & Remote controller \\
\hline IC card reader & User Interface Bridge & Embedded IC card controller. \\
\hline $\begin{array}{l}\text { Upgrade / technical } \\
\text { support interface }\end{array}$ & USB 1.1 interface / Serial interface: RS232 & USB 2.0 / Serial interface: RS232 \\
\hline $\begin{array}{l}\text { External storage } \\
\text { interface }\end{array}$ & USB 1.1 Interface. & USB 2.0 Interface. \\
\hline Generic Interface & USB 1.1 Interface. & USB 2.0 Interface. \\
\hline Return Channel & Ethernet $10 / 100$ trough Intel $82562 \mathrm{ET}$ & Ethernet $10 / 100$ \\
\hline
\end{tabular}




\section{Acknowledgements}

This project was sponsored by the Brazilian Fund for the Telecommunications Developing FUNTEL, under the SBTVD MC/MCT/FINEP/FUNTTEL-TV Digital 05/2004 contract: $01.05 .0103 .00,2038$. We would like to thank several people that have made this project a reality. Many thanks to all researchers on the Access Device reference Architecture consortia for their inspiring and fruitful contributions to this research, especially to $\mathrm{Mr}$. Domingos Kiriakos Stravidis who managed this project between 2004 and 2006 in the University of São Paulo, at the Escola Politécnica da USP particularly the Laboratory of Integrated Systems, to Eduardo Marques, ICMC USP; Valentin Obac Roda, EESC USP; Antonio Carlos Cavalcanti, UFPB; Luiz Marcos, UFRN; Marcelo Moreno, PUC-RIO; ST Microeletronics; Intel and Xilinx Representatives in Brazil. Finally we are grateful to Ms. Irene Ficheman who did a final english revision of this paper.

\section{REFERENCES}

[1] Y. Wu, S. Hirakawa, U. H. Reimers, J. Whitaker. Overview of digital television development worldwide. In Proceedings of the IEEE. 94(1): 821, Jan. 2006.

[2] P. Woolich. The digital hubbub. IEEE Spectrum. Pages: 26-32, Jan. 2002.

[3] G. Bedicks Jr., F. Yamada, F. Sukys, C. E. S. Dantas, L. T. M. Raunheitte, C. Akamine. Results of the ISDB-T system tests, as part of digital TV study carried out in Brazil. In IEEE Transactions on Broadcasting. 52(1): 38- 44, March. 2006.

[4] G. Bedicks Jr., F. Yamada, F. Sukys, C. E. S. Dantas, L. T. M. Raunheitte, C. Akamine. Digital Signal Disturbed by Impulsive Noise. In IEEE Transactions On Broadcasting. 51(3): 322-328, Sep. 2005.

[5] T. Yoshimura. Conditional Access System for Digital Broadcasting in Japan. In Proceedings of the IEEE. 94(1): 318 - 322, Jan. 2006.

[6] M. Sakurai. Digital Television Receiver for ISDB. In Proceedings of the IEEE. 94(1): 323-326, Jan. 2006.

[7] R. J. Crinon, D. Bhat, D. Catapano, G. Thomas, J. T. Van Loo, G. Bang. Data Broadcasting and Interactive Television. Proceedings of the IEEE. 94(1): 102-118, Jan. 2006.

[8] R. A. Vaz, E. R. Carvalho, M. K. Zuffo. The convergence of diverse network technologies in only one step-top box (for the future Brazilian scene). In IEEE Broadcast Symposium, 56, Washington DC. New York, 2006.

[9] Y. Wu, E. Pliszka, B. Caron, P. Bouchard, G. Chouinard. Comparison of terrestrial DTV transmission systems: The ATSC 8-VSB, the DVB-T COFDM, and ISDB-T BST-OFDM. In IEEE Transactions on Broadcasting. 46(2), Jun. 2000.

[10] ARIB STD-B31 V. 1.2, Transmission system for digital terrestrial television broadcasting ARIB standard, Association of Radio Industries and Businesses, Jan. 24, 2002.

[11] Presidential Act 4901: The SBTVD Launch, $26^{\text {th }}$ November 2003, available on line http://www.planalto.gov.br, in Portuguese.

[12] Presidential Act 5820 The SBTVD Decision, $29^{\text {th }}$ July 2006, available on line http://www.planalto.gov.br, in Portuguese.

[13] ANATEL. National Agency of Telecommunication. On line: http://www.anatel.gov.br Last access in January 2007.

[14] ABINEE, Brazilian Electrical and Electronics Industry Association. On line: http://www.abinee.org.br/ing/index.htm Last access in January 2007.

[15] S. Chen Niu. A stochastic formulation of the Bass model of new-product diffusion. In Review of Marketing Science Working Papers. 1(4): Working Paper 1, 2002.

[16] F. M. Bass. A new product growth for model consumer durables. In Management Sci. 15:215227, 1969.

[17] ITU-R BS.775-1. Multichannel stereophonic sound system with and without accompanying picture. 1994 (ver. 2002)

[18] R. R. A. Faria, et al. Objective evaluation of audio compression standards and tools for digital TV applications. 56th Annual IEEE Broadcast Symposium. Proceedings. Washington, 2006.

[19] ISO/IEC 14496-3 (2005): Information technology - Coding of audio-visual objects - Part 3: Audio. ISO, 2005.

[20] S. Bonnici. Which channel is that on?: A design model for electronic programme guides. In Proceedings of the 1st European Conference on Interactive Television: from Viewers to Actors. 
University of Brighton, 2003.

[21] J. Carey. An Ethnographic Study of Interactive Television. Conference On Interactive Television. Edinburgh, Scotland: University of Edinburgh, 1996.

[22] A. Dix, J. E. Finlay, G. D. Abowd, R. Beale. Human-Computer Interaction. Prentice Hall, 1998.

[23] S. M. Drucker, A. Glatzer, S. De Mar, C. Wong. SmartSkip: consumer level browsing and skipping of digital video content. In $\mathrm{CHI}$ '02: Proceedings of the SIGCHI conference on Human factors in computing systems. New York: ACM Press: 219226, 2002.

[24] J. Freeman, J. Lessiter. ITC-UsE: Ease of Use and Knowledge of Digital and Interactive Television: Results. London: University of London, 2001.

[25] J. Freeman, J. Lessiter. Easy TV 2002 Research Report. London: University of London, 2003.

[26] M. Gawlinski. Interactive Television Production. Focal Press: 288, 2003.

[27] A. Hedman. A Media Rich Interface vs A Simple Interface for Interactive Television. In Proceedings of E-Learn 2002 World Conference. Montreal, Canada, 2002.

[28] J. Klein, S. Karger, K. Sinclair. Digital Television For All: A report on usability and accessible design. Cambridge, UK: The Generics Group, 2003.

[29] T. Koltringer, M. Tomitsch, K. Kappel, D. Kalbeck. Implications for Designing the User Experience of DVD Menus. In CHI '05 extended abstracts on Human factors in computing systems. ACM Press: 1565-1568, 2005.

[30] J. Nielsen. Coordinating UI for Consistency. Morgan Kaufmann: 156, 2002.

[31] C. Quico, M. J. Damásio. Televisão Digital e Interactiva: a modelação social como variável na avaliação de usabilidade. In Oficina TV Interativa IHC 2004. Curitiba, Brasil, 2004.

[32] B. Shneiderman. Designing The User Interface: Strategies for effective human-computer interaction. Addison Wesley, 1998.

[33] D. D. Spinellis. The Information Furnace: Consolidated Home Control. In Personal Ubiquit. Comput. No. 7: 53-69, Londres, Springer-Verlag, 2003.

[34] J. P. Evain, H. Murret-Labarthe. TV- Anytime Phase 1 - A Decisive Milestone In Open Standardisation For Personal Video Recorders. In
[35] S. Berkovits, S. Chokhani, J. A. Furlong, J. A. Geiter, J. C. Guild. Public Key Infrastructure Study: Final Report. Produced by the MITRE Corporation for NIST, April 1994. 